\title{
Prevalence and Potential Factors Related to Irreversible Chemotherapy-induced Amenorrhea in Premenopausal Breast Cancer Patients
}

\author{
Pannarat Khunthong ${ }^{1}$, Prapaporn Suprasert ${ }^{1}$, Areewan Somwangprasert ${ }^{2}$
}

${ }^{1}$ Department of Obstetrics and Gynecology, Faculty of Medicine, Chiang Mai University, Thailand. ${ }^{2}$ Department of Surgery, Faculty of Medicine, Chiang Mai University, Thailand.

\begin{abstract}
Objective: To evaluate the prevalence and potential factors related to irreversible chemotherapy-induced amenorrhea (CIA) in premenopausal women with breast cancer. Methods: First diagnosis breast cancer women in Stages I-III who had menstruation within three months before receiving chemotherapy and completed a course of treatment were interviewed about the menstrual cycle after a complete course of chemotherapy and the subsequent menstrual status. Clinical data were retrospectively reviewed. Age at starting chemotherapy was calculated for an optimal cut-off point by using the receiver operating characteristic curve to predict irreversible CIA. The clinicopathological variables were compared using univariate and multivariate analysis to identify the independent factors related to irreversible CIA. Results: One hundred and fifty-four premenopausal breast cancer women who met the inclusion criteria were interviewed. They were treated with chemotherapy between October 1999 and September 2018. The median age at the start of treatment was 43.5 years. One hundred forty-two patients (92.2\%) developed CIA and 37 cases subsequently resumed menstruation (RM). Thus, the prevalence of irreversible CIA was $68.2 \%$. The group $>45$ years of age, estrogen receptor-positive, progesterone receptor-positive and maintenance treatment with tamoxifen significantly developed irreversible CIA in univariate analysis. However, only the $>45$-year-old group was an independent factor for the CIA with an adjusted odds ratio of 23.04. Conclusion: Nearly $70 \%$ of premenopausal breast cancer women developed irreversible CIA and the independent factor for this event was being older than 45-years-old when receiving chemotherapy.
\end{abstract}

Keywords: Breast cancer- chemotherapy- amenorrhea

Asian Pac J Cancer Care, 5 (3), 167-172

Submission Date: 05/08/2020Ａcceptance Date: 07/08/2020

\section{Introduction}

Breast cancer is the most common female cancer in the world with the age-standardized incidence rate (ASR) and mortality rate as high as 46.3 and 13.0 per 100,000 persons-year, respectively. In Thailand, breast cancer also ranks as the number one female cancer with the ASR as 34.4 per 100,000 people per year [1]. The principle treatment of breast cancer included surgery followed by adjuvant chemotherapy, radiotherapy or hormonal therapy depending on the stage and the specific receptors [2]. One major concern was the issue of breast cancer trending to occur in young aged women. Globocan 2018 reported ASR of breast cancer women younger than 45 years-old as 13.4 per 100,000 people per year [1]. In this age group, the cytotoxic chemotherapy used as adjuvant drugs for treating breast cancer such as doxorubicin, cyclophosphamide, docetaxel, paclitaxel, methotrexate, and 5-fluorouracil affected the ovarian function by destroying and eliminating the primordial follicles and subsequently induced transient or permanent amenorrhea [3]. These effects may result in physiological changes associated with menopausal problems like osteoporosis, hypercholesterolemia, hot flushes, genitourinary symptom, psychologic stress, weight gain and infertility [4]. Due to the prohibition for giving hormonal therapy to breast cancer survivors, the resuming of menstruation after discontinued chemotherapy is very important to reduce

Corresponding Author:

Dr. Prapaporn Suprasert

Department of Obstetrics and Gynecology, Faculty of Medicine, Chiang Mai University, Thailand.

Email: psuprase@gmail.com 
such problems. The incidence of chemotherapy-induced amenorrhea (CIA) from a previous report varied from $10 \%$ to $93 \%$ depending on the definition of CIA, the differences in follow up time and characteristics of patients in each study [5]. However, the rate of CIA and the prevalence of the resumption of menstruation (RM) in Thai premenopausal breast cancer patients is limited. Therefore, we conducted the current study to identify these data and the factors related to irreversible menstruation.

\section{Materials and Methods}

This prospective study was conducted after approval from the Ethics Committee of the Faculty of Medicine, Chiang Mai University. All newly diagnosed stage I-III breast cancer patients treated between October 1999 and September 2018 who had regular menstruation with the last menstrual period occurring within three months before starting chemotherapy and free of disease more than 12 months after a complete course of chemotherapy were invited to participate in this study. All of them communicated well in the Thai language and could respond to the well-trained interviewers regarding their history of menstruation after just finishing the first course of chemotherapy and the subsequent menstrual status. The interview process was conducted at the Outpatient Department of Surgery when the patients came to follow up after completing their treatment. All eligible patients gave informed consent before participation in this project. Patients who developed bilateral breast cancer, previous hysterectomy, received GnRH analog and could not provide their menstrual history were not included in the study. The demographic data, the breast cancer characteristics and the details of the anti-cancer treatment of all participants were reviewed and recorded. We defined the CIA as amenorrhea for longer than or equal to three months. The resumption of menstruation was defined as at least two cycles of menstruation bleeding after CIA.

The sample size for this trial was estimated on the basis of a prior study that revealed $90 \%$ of premenopausal women developed CIA [6]. The 95 inter-percentile reference intervals for calculation accommodated the possibility of a loss of follow up participants. Finally, this study needed to enroll about 150 participants.

Statistical analysis of the data was carried out using the IBM SPSS Statistics for Windows program (Version 22). Descriptive statistics were used to summarize patient characteristics and menstrual history. Chi-square or Fisher's exact test was used for comparative analysis of the factors between irreversible CIA and resuming of menstruation groups to calculate the odds ratio of categorical variables. A receiver operating characteristic curve (ROC) was used to assess the discriminative value and the best cut-off value of the possible factors was determined to further predict the irreversible CIA. Binary logistic regression analysis with an enter method was used to identify the potential independent predictive factors for continuous CIA. A p-value of $<0.05$ was considered statistically significant.

\section{Results}

One hundred and fifty-four patients who met the inclusion criteria were interviewed in the study period. The median age at the interviewed time and at the time of receiving chemotherapy was 49 and 43.5 years old, respectively. The median time from completed first-line chemotherapy to study entry was four years with a range of 1-20 years. The mean body mass index was $23.87 \mathrm{~kg} / \mathrm{m}^{2}$ and the median tumor size was $2.5 \mathrm{~cm}$. About $40 \%$ of the studied patients did not use any contraception before starting chemotherapy while $20 \%$ of them used oral contraceptive pills. The most common histology was invasive ductal carcinoma and about $72 \%$ presented with positive estrogen receptor (ER) and tamoxifen was given in three-fourths of the patients. Nearly $90 \%$ were still free of disease at the interview time. The details of the clinical data were noted in Table 1.

The type of chemotherapy was presented in Table 2 . The three most frequent regimens were fluorouracil+ adriamycin+cyclophosphamide (FAC), Adriamycin plus cyclophosphamide (AC) and AC followed by paclitaxel.

Regarding menstruation status, 142 patients $(92.2 \%)$ developed the CIA after completing first-line chemotherapy while 12 cases still had menstruation while receiving chemotherapy. However, 37 cases of the CIA patients $(35.2 \%)$ resumed normal menstruation indicating that $68.2 \%$ of these participants developed irreversible CIA.

To identify the independent factors related to the resumption of menstruation by using the ROC curve, only age at the cut-off point of 45 years old was the potential factor as shown in Figure 1. Furthermore, Table 3 demonstrated the significant factors that might predict irreversible CIA. The results showed that the age group older or equal to 45 years, ER-positive,

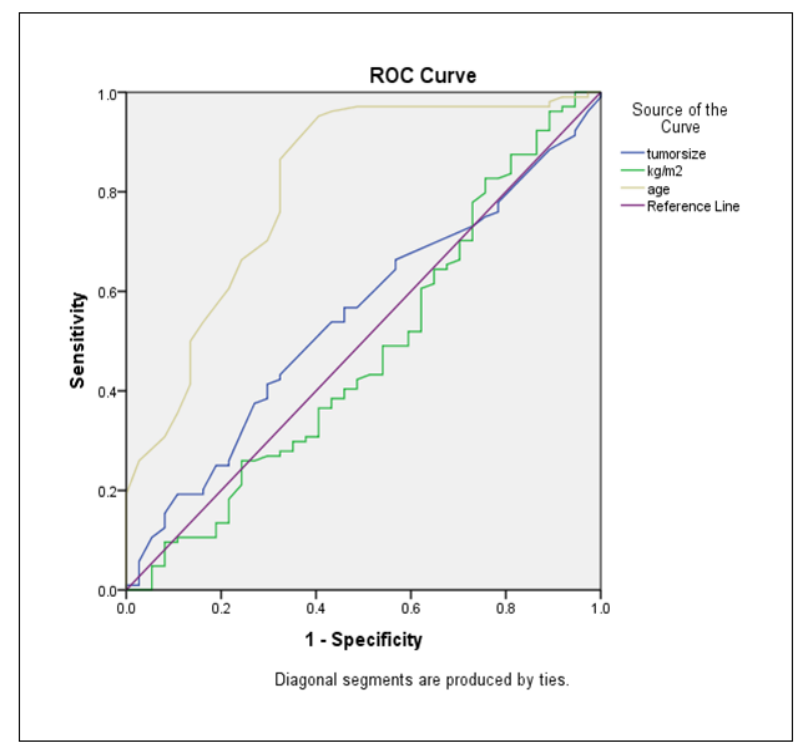

Figure 1. Receiver-Operating-Characteristic (ROC) and Area Under the Curve (AUC) for Clinical Characteristics to Predict Chemotherapy-Induced Amenorrhea.

Test, Age; AUC, 0.812; 95\% CI, 0.726-0.899; Cut-off Point, 45; Sensitivity, 0.865; Specificity, 0.324; P-Value, $<0.001$ 
Table 1. Clinical Characteristics $\mathrm{N}=154$

\begin{tabular}{|c|c|}
\hline Median age of interviewed (range: year) & $49(24-65)$ \\
\hline Median age of received chemotherapy (range: year) & $43.5(23-55)$ \\
\hline Mean BMI (SD: kg/m²) & $23.87(3.90)$ \\
\hline Median tumor size (range: $\mathrm{cm}$ ) & $2.5(0.9-11.0)$ \\
\hline \multicolumn{2}{|l|}{ Last contraception (before chemotherapy began) (\%) } \\
\hline Oral contraceptive pill & $32(20.8)$ \\
\hline Depo- Medroxy Progesterone Acetate (DMPA) & $6(3.9)$ \\
\hline Intrauterine device & $2(1.3)$ \\
\hline Tubal resection & $34(22.1)$ \\
\hline Condom & $6(3.9)$ \\
\hline Coitus interruptus & $10(6.5)$ \\
\hline None & $64(41.6)$ \\
\hline \multicolumn{2}{|l|}{ FIGO staging $(\%)$} \\
\hline IA & $35(22.7)$ \\
\hline IB & $1(0.6)$ \\
\hline IIA & $67(43.5)$ \\
\hline IIB & $25(16.2)$ \\
\hline IIC & $1(0.6)$ \\
\hline IIIA & $21(13.6)$ \\
\hline IIIB & $1(0.6)$ \\
\hline IIIC & $3(1.9)$ \\
\hline \multicolumn{2}{|l|}{ Histology $(\%)$} \\
\hline Ductal carcinoma in situ (DCIS) & $2(1.3)$ \\
\hline Ductal carcinoma & $1(0.6)$ \\
\hline Encapsulated papillary carcinoma & $1(0.6)$ \\
\hline Invasive ductal carcinoma (IDCA) & $135(87.7)$ \\
\hline Invasive lobular carcinoma & $3(1.9)$ \\
\hline Invasive papillary carcinoma & $2(1.2)$ \\
\hline Micropapillary carcinoma & $1(0.6)$ \\
\hline Mixed mucinous with IDCA & $1(0.6)$ \\
\hline Mucinous carcinoma & $7(4.5)$ \\
\hline Tubular carcinoma & $1(0.6)$ \\
\hline \multicolumn{2}{|c|}{ Menstrual status after completed 1st line chemotherapy course (\%) } \\
\hline Irreversible amenorrhea & $105(68.2)$ \\
\hline Resumed menstruation & $37(24.0)$ \\
\hline Ongoing menstruation & $12(7.8)$ \\
\hline \multicolumn{2}{|l|}{ Current status of menstruation (interview day) (\%) } \\
\hline Amenorrhea & $118(76.6)$ \\
\hline Normal menstruation & $36(23.4)$ \\
\hline \multicolumn{2}{|l|}{ Receptor positive $(\%)$} \\
\hline Estrogen & $112(72.7)$ \\
\hline Progesterone & $105(31.8)$ \\
\hline $\begin{array}{l}\text { Human epidermal growth factor receptor } 2 \\
\text { (HER2) }\end{array}$ & $37(24.0)$ \\
\hline Received tamoxifen (\%) & $116(75.3)$ \\
\hline \multicolumn{2}{|l|}{ Current status $(\%)$} \\
\hline Free of disease & $125(88.0)$ \\
\hline Recurrence & $15(10.6)$ \\
\hline Developed other malignancy & $2(1.4)$ \\
\hline
\end{tabular}

progesterone receptor (PR) positive and tamoxifen usage were significant in univariate analysis while only the group older or equal to 45 years old was significant in multivariate analysis. Thus, the age group over or equal to 45 years old was an independent factor related to CIA.

Table 4 summarizes 12 patients who still had menstruation while receiving chemotherapy. Their range age was between 23 and 47 years old and ten patients continued normal menstruation while two patients were in menopause at the interviewing time. All these patients received cyclophosphamide combined with other chemotherapy such as adriamycin, fluorouracil, paclitaxel, etc. All except two patients were still free of disease at the interview time while each the remainder developed a recurrent and second malignancy.

\section{Discussion}

The rate of CIA in breast cancer patients who received first-line chemotherapy in the present study was $92.2 \%$ and $35.2 \%$ of them resumed menstruation while $7.8 \%$ of all participants still developed menstruation during and after receiving chemotherapy. This prevalence rate was similar to a previous publication from Japan. Kota et al. [7] studied menstruation in 101 premenopausal Stage I-III hormonal receptor-positive Japanese breast cancer women who received chemotherapy. The authors defined CIA as the disappearance of periodic menstruation during chemotherapy and if the menstruation appeared after finishing the course of chemotherapy, this state was defined as a resumption of menstruation. CIA in their study was $96 \%$ and about $40 \%$ of them resumed menstruation with a variation of 1-3 years depending on the age. All patients less than 30 years of age resumed menstruation within one year while $60 \%$ of patients aged more than 35-year-old resumed menstruation around 2-3 years. Another study from China, Liem et al [6], reported the rate of CIA in premenopausal breast cancer women aged less than 45 -year-old as $91 \%$ and the rate of resumption of menstruation of $66.7 \%$. The definition of CIA in this study was amenorrhea more than three months while receiving chemotherapy or within 12 months after completion of

Table 2. Chemotherapy Regimen

\begin{tabular}{lc}
\hline Regimen & $\mathrm{N}(\%)$ \\
\hline $\mathrm{AC}$ & $38(24.6)$ \\
$\mathrm{AC}+\mathrm{T}$ & $39(25.3)$ \\
$\mathrm{AC}+\mathrm{TH}$ & $6(3.8)$ \\
$\mathrm{FAC}$ & $44(28.6)$ \\
$\mathrm{FEC}$ & $7(4.5)$ \\
$\mathrm{CMF}$ & $6(3.9)$ \\
FAC $+\mathrm{T}$ & $5(3.2)$ \\
Other* & $9(5.8)$ \\
\hline
\end{tabular}

*Other, AC + FAC + AC + TH (1), CMF + AC (1), FAC + AC (1), $\mathrm{FAC}+\mathrm{TH}(1), \mathrm{FEC}+\mathrm{D}(2), \mathrm{FEC}+\mathrm{T}(1), \mathrm{FEC}+\mathrm{TH}(1), \mathrm{TC}(1) ; \mathrm{AC}$ Adriamycin + cyclophosphamide, FAC; fluouracil + Adriamycin + cyclophosphamide, FEC; fluouracil + epirubicin + cyclophosphamide, MF; cyclophosphamide + methotrexate, fluorouracil, T; paclitaxel, TH; trastuzumab (Herceptin)'D; docetaxel 
Table 3. Factors to Predict Chemotherapy-Induced Amenorrhea

\begin{tabular}{|c|c|c|c|c|c|c|c|}
\hline \multirow[t]{2}{*}{ Factors } & \multicolumn{2}{|c|}{ Number of Patients Divided by Menstrual Status } & \multirow{2}{*}{$\begin{array}{c}\text { Total } \\
(\%)\end{array}$} & \multicolumn{2}{|c|}{ Univariate Analysis* } & \multicolumn{2}{|c|}{ Multivariate Analysis $\dagger$} \\
\hline & CIA (\%) & $\mathrm{RM}(\%)$ & & OD $(95 \% \mathrm{CI})$ & P-Value & Adjusted OR $(95 \% \mathrm{CI})$ & P-Value \\
\hline Age $>45$ years & $57(40.1)$ & $2(1.4)$ & $59(41.5)$ & 20.781 & $<0.001$ & 23.041 & $<0.001$ \\
\hline Age $<45$ years & $48(57.8)$ & $35(24.6)$ & $83(58.5)$ & $(4.751-90.906)$ & & & \\
\hline ER & & & & & 0.026 & 1.724 & 0.685 \\
\hline Positive & $85(59.9)$ & $23(16.2)$ & $108(76.1)$ & 2.587 & & & \\
\hline Negative & $20(14.1)$ & $14(9.9)$ & $34(23.9)$ & $(1.135-5.896)$ & & & \\
\hline PR & & & & & 0.005 & 2.521 & 0.253 \\
\hline Positive & $82(57.7)$ & $20(14.1)$ & $102(71.8)$ & 3.03 & & & \\
\hline Negative & $23(16.2)$ & $17(12.0)$ & $40(28.2)$ & $(1.369-6.710)$ & & & \\
\hline HER2 & $24(16.9)$ & $11(7.7)$ & $35(24.6)$ & 0.7 & 0.404 & 0.981 & 0.973 \\
\hline Positive & $81(57.0)$ & $26(18.3)$ & $107(75.4)$ & $(0.303-1.621)$ & & & \\
\hline \multicolumn{8}{|l|}{ Negative\# } \\
\hline Tamoxifen & $88(62.0)$ & $24(16.9)$ & $112(78.9)$ & 2.804 & 0.015 & 0.518 & 0.675 \\
\hline Yes & $17(12.0)$ & $13(9.2)$ & $30(21.1)$ & $(1.197-6.571)$ & & & \\
\hline \multicolumn{8}{|l|}{ No } \\
\hline Stage & & & & & 0.124 & 0.372 & 0.095 \\
\hline I & $21(14.8)$ & $12(8.5)$ & $33(23.2)$ & 0.521 & & & \\
\hline II\&III & $84(59.2)$ & $25(17.6)$ & $109(76.8)$ & $(0.225-1.204)$ & & & \\
\hline Chemotherapy & & & & & 0.867 & 0.811 & 0.729 \\
\hline $\mathrm{AC}$ regimen & $27(19.0)$ & $9(6.3)$ & $36(25.4)$ & 1.077 & & & \\
\hline Other & $78(54.9)$ & $28(19.7)$ & $106(74.6)$ & $(0.452-2.569)$ & & & \\
\hline Lasted contraception & & & & 0.935 & 0.876 & 0.944 & 0.91 \\
\hline Hormone-relatedd & $27(19.0)$ & $10(7.0)$ & $37(26.1)$ & $(0.401-2.181)$ & & & \\
\hline \multicolumn{8}{|l|}{ Non-hormone related } \\
\hline & $78(54.9)$ & $27(19.0)$ & $105(73.9)$ & & & & \\
\hline Response & $95(66.9)$ & $32(22.5)$ & $127(89.4)$ & 1.484 & 0.497 & 1.308 & 0.687 \\
\hline No recurrence & $10(7.0)$ & $5(3.5)$ & $15(10.6)$ & $(0.472-4.668)$ & & & \\
\hline
\end{tabular}

*chi-square test; †Binary regression analysis (Enter); CIA, chemotherapy induced amenorrhea; RM, resumed menstruation; OR, odds ratio; $95 \%$ CI, 95\% confidence interval; ER , estrogen receptor; PR, progesterone receptor; HER2, human epidermal growth factor receptor 2; AC, Adriamycin + cyclophosphamide; \# Equivocal, 25 cases.

chemotherapy while the resumption of menstruation was defined as at least two cycles of menstruation after CIA. Their results corresponded to our study except for the rate of resumption of menstruation. Our study found the rate of resume menstruation only $24.6 \%$ in patients younger than 45 years old. This difference might be from the variant of the number of participants and the chemotherapy regimens. Moreover, Shin et al. [8] recently reported the rate of CIA in 237 premenopausal Korean breast cancer women aged 20-44 years who treated with chemotherapy after surgery. They found the rate of CIA as $61.6 \%$ and the rate of irreversible CIA was $13.1 \%$ at one year. Due to the varied rate of CIA in various publications, Zavos and Valachis [9] performed meta-analysis from 75 studies that presented the data of CIA and found that the pooled rate of CIA was $55 \%$ and the rate of CIA was increased by age. The authors summarized both ages more than 40-year-old and the use of tamoxifen were the risk factors for developing CIA.

Regarding independent factors related to CIA, our study revealed only age older than 45 years-old impacted irreversible CIA. This result was similar to previous reports that showed younger ages related to the resumption of menstruation [6-10]. However, Meng et al. [10] published their study about this issue in 73 premenopausal breast cancer women who received adjuvant chemotherapy for early-stage breast cancer (Stages I-III) and found that CIA significantly related to age at diagnosis and tamoxifen usage. This result corresponded to the meta-analysis from Zavos and Valachis mentioned above [9]. In our study, $75.3 \%$ of the participants reported tamoxifen usage and this factor was not significant for permanent CIA in multivariate analysis. This different outcome might be for various reasons such as the duration of tamoxifen usage, the chemotherapy regimen, the ethnicity, and genetic backgrounds. Ruddy et al. [11] studied premenopausal breast cancer women younger than 45 years old and suggested that genetic variations with rs 147451859 on chromosome 15 and rs 17587029 on chromosome 2 were associated with resumption of menses after chemotherapy. Furthermore, Kim et al. [12] also reported 38.9\% of premenopausal breast cancer women still had regular menstruation while using tamoxifen.

Concerning prognosis in patients with CIA, Zhou et al. [13] performed meta-analysis from 13 eligible studies that recruited over five thousand breast cancer 
Table 4. Clinical Characteristics of Patients Still Menstruating During Chemotherapy $(\mathrm{N}=12)$

\begin{tabular}{|c|c|c|c|c|c|c|c|c|c|c|c|c|}
\hline SN & $\begin{array}{l}\mathrm{Age}^{1} \\
\text { (year) }\end{array}$ & $\begin{array}{l}\text { Age }^{2} \\
\text { (years) }\end{array}$ & $\begin{array}{c}\mathrm{BMI} \\
\left(\mathrm{Kg} / \mathrm{M}^{2}\right)\end{array}$ & Stage & Histology & ER & PR & HER2 & Tamoxifen & Chemotherapy & $\begin{array}{c}\text { Current } \\
\text { menstrual } \\
\text { status }\end{array}$ & $\begin{array}{c}\text { Current } \\
\text { cancer } \\
\text { status }\end{array}$ \\
\hline 8 & 26 & 30 & 18.96 & IIB & IDCA & Positive & Positive & Equivocal & Yes & $\mathrm{ACx} 4+\mathrm{Tx} 4$ & $\begin{array}{c}\text { Still } \\
\text { menstruating }\end{array}$ & $\mathrm{CR}$ \\
\hline 40 & 40 & 53 & 33.33 & IIA & IDCA & Negative & Negative & Negative & No & FECx 6 & $\begin{array}{c}\text { Still } \\
\text { menstruating }\end{array}$ & $\mathrm{CR}$ \\
\hline 66 & 40 & 47 & 21.29 & I & IDCA & Negative & Negative & Equivocal & No & FAC $\times 6$ & $\begin{array}{c}\text { Still } \\
\text { menstruating }\end{array}$ & $\mathrm{CR}$ \\
\hline 74 & 36 & 38 & 24.52 & IIIA & IDCA & Negative & Negative & Positive & No & $\mathrm{ACx} 4+\mathrm{Tx} 4$ & $\begin{array}{c}\text { Still } \\
\text { menstruating }\end{array}$ & $\mathrm{CR}$ \\
\hline 75 & 28 & 43 & 19.07 & IIA & IDCA & Negative & Negative & Negative & No & FACx 6 & Menopause & $\begin{array}{c}\text { Developed } \\
\text { secondary } \\
\text { cancer }\end{array}$ \\
\hline 123 & 33 & 34 & 30.39 & IIB & IDCA & Negative & Negative & Equivocal & No & $\mathrm{ACx} 4+\mathrm{Tx} 4$ & $\begin{array}{c}\text { Still } \\
\text { menstruating }\end{array}$ & $\mathrm{CR}$ \\
\hline 143 & 47 & 53 & 20.66 & IIA & IDCA & Positive & Negative & Positive & Yes & $\mathrm{ACx} 4+\mathrm{Tx} 4$ & Menopause & $\mathrm{CR}$ \\
\hline 164 & 30 & 45 & 21.78 & IA & $\begin{array}{c}\text { Tubula } \\
\text { CA }\end{array}$ & Negative & Negative & Negative & No & CMF $\times 6$ & Menopause & Recurrence \\
\hline 172 & 37 & 40 & 21.97 & IIIA & IDCA & Negative & Negative & Negative & No & $\mathrm{ACx} 4+\mathrm{Tx} 4$ & $\begin{array}{c}\text { Still } \\
\text { menstruating }\end{array}$ & $\mathrm{CR}$ \\
\hline 176 & 27 & 35 & 21.48 & IA & IDCA & Negative & Negative & Negative & No & FAC $\times 6$ & $\begin{array}{c}\text { Still } \\
\text { menstruating }\end{array}$ & $\mathrm{CR}$ \\
\hline 186 & 30 & 33 & 20.2 & IIB & IDCA & Positive & Positive & Equivocal & Yes & $\mathrm{AC} \times 4+\mathrm{TH} \times 4$ & $\begin{array}{c}\text { Still } \\
\text { menstruating }\end{array}$ & $\mathrm{CR}$ \\
\hline 188 & 23 & 24 & 28.55 & IIA & $\begin{array}{c}\text { Mucinous } \\
\text { CA }\end{array}$ & Positive & Positive & Negative & Yes & $\mathrm{AC} \times 4$ & $\begin{array}{c}\text { Still } \\
\text { menstruating }\end{array}$ & $\mathrm{CR}$ \\
\hline
\end{tabular}

$\mathrm{Age}^{1}$, at received chemotherapy, $\mathrm{Age}^{2}$, age at interview, BMI; body mass index, ER; estrogen receptor, PR; progesterone receptor, HER2; human epidermal growth factor receptor 2, IDCA; invasive ductal carcinoma, AC; Adriamycin+cyclophosphamide, T; paclitaxel, CR; complete response, FEC; fluouracil + epirubicin + cyclophosphamide, FAC; fluouracil + Adriamycin + cyclophosphamide, CMF; cyclophosphamide + methotrexate, fluorouracil, TH; trastuzumab (Herceptin), CA; carcinoma

patients to assess the exact prognostic value of CIA and reported that CIA was associated with improvement of disease-free and overall survival. However, our study did not find this benefit from irreversible CIA. The recurrence rate in patients with irreversible CIA and resumption of menstruation was not significantly different. Moreover, with 12 patients who still had normal menstruation, ten patients were still free of disease. This non-similar result might be from the limited number of our participants to compare this treatment outcome between patients with and without CIA.

The strength of our study was that all of the participants were treated in one institution. This should decrease the level of variation from the type of treatment. However, due to the nature of a retrospective study, some data was missing and more details of menstruation such as regularity before CIA and the time of resuming menstruation were not available.

In conclusion, over $90 \%$ of premenopausal women experienced CIA and one-third of them could be recover while less than $10 \%$ still had normal menstruation. The age over 45 years-old was the only independent factor related to irreversible CIA. This study did not find the association of permanent CIA and the outcome of treatment in terms of recurrence rate.

\section{References}

1. Bray F, Ferlay J, Soerjomataram I, Siegel RL, Torre LA, Jemal A. Global cancer statistics 2018: GLOBOCAN estimates of incidence and mortality worldwide for 36 cancers in 185 countries. CA: A Cancer Journal for Clinicians. 2018 09 12;68(6):394-424. https://doi.org/10.3322/caac.21492.

2. Kumar Tyagi N, Dhesy-Thind S. Clinical practice guidelines in breast cancer. Current Oncology. 201806 14;25:151. https://doi.org/10.3747/co.25.3729.

3. Torino F, Barnabei A, De Vecchis L, Appetecchia M, Strigari L, Corsello SM. Recognizing menopause in women with amenorrhea induced by cytotoxic chemotherapy for endocrine-responsive early breast cancer. Endocrine-Related Cancer. 201201 12;19(2):R21-R33. https://doi.org/10.1530/ erc-11-0199.

4. Takahashi TA, Johnson KM. Menopause. Medical Clinics of North America. 2015 05;99(3):521-534. https://doi. org/10.1016/j.mena.2015.01.006.

5. Torino F, Barnabei A, De Vecchis L, Sini V, Schittulli F, Marchetti P, Corsello SM. Chemotherapy-induced ovarian toxicity in patients affected by endocrine-responsive early breast cancer. Critical Reviews in Oncology/ Hematology. 2014 01;89(1):27-42. https://doi.org/10.1016/j. critrevonc.2013.07.007.

6. Liem GS, Mo FKF, Pang E, Suen JJS, Tang NLS, Lee KM, Yip CHW, Tam WH, Ng R, Koh J, Yip CCH, Kong GWS, Yeo W. Chemotherapy-Related Amenorrhea and Menopause in Young Chinese Breast Cancer Patients: Analysis on Incidence, Risk Factors and Serum Hormone Profiles. Chu P. PLOS ONE. 2015 Oct 20;10(10):e0140842. https://doi. org/10.1371/journal.pone.0140842.

7. Koga C, Akiyoshi S, Ishida M, Nakamura Y, Ohno S, Tokunaga E. Chemotherapy-induced amenorrhea and the resumption of menstruation in premenopausal women with hormone receptor-positive early breast cancer. Breast 
Cancer. 201702 27;24(5):714-719. https://doi.org/10.1007/ s12282-017-0764-1.

8. Shin JJ, Choi YM, Jun JK, Lee K, Kim T, Han W, Im S. Amenorrhea and Menopause in Patients with Breast Cancer after Chemotherapy. Journal of Breast Cancer. 2019;22(4):624. https://doi.org/10.4048/jbc.2019.22.e53.

9. Zavos A, Valachis A. Risk of chemotherapy-induced amenorrhea in patients with breast cancer: a systematic review and meta-analysis. Acta Oncologica. 201604 22;55(6):664670. https://doi.org/10.3109/0284186x.2016.1155738.

10. Meng K, Tian W, Zhou M, Chen H, Deng Y. Impact of chemotherapy-induced amenorrhea in breast cancer patients: the evaluation of ovarian function by menstrual history and hormonal levels. World Journal of Surgical Oncology. 2013;11(1):101. https://doi.org/10.1186/1477-7819-11-101

11. Ruddy KJ, Schaid DJ, Partridge AH, Larson NB, Batzler A, Häberle L, Dittrich R, Widschwendter P, Fink V, Bauer E, Schwitulla J, Rübner M, Ekici AB, Aivazova-Fuchs V, Stewart EA, Beckmann MW, Ginsburg E, Wang L, Weinshilboum RM, Couch FJ, Janni W, Rack B, Vachon C, Fasching PA. Genetic predictors of chemotherapyrelated amenorrhea in women with breast cancer. Fertility and Sterility. 2019 Oct;112(4):731-739.e1. https://doi. org/10.1016/j.fertnstert.2019.05.018

12. Kim H, Han W, Ku S, Suh CS, Kim SH, Choi YM. Feature of amenorrhea in postoperative tamoxifen users with breast cancer. Journal of Gynecologic Oncology. 2017;28(2). https://doi.org/10.3802/jgo.2017.28.e10

13. Zhou Q, Yin W, Du Y, Shen Z, Lu J. Prognostic impact of chemotherapy-induced amenorrhea on premenopausal breast cancer. Menopause. 2015 Oct;22(10):1091-1097. https://doi. org/10.1097/gme.0000000000000440

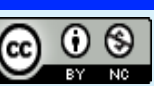

This work is licensed under a Creative Commons AttributionNon Commercial 4.0 International License. 